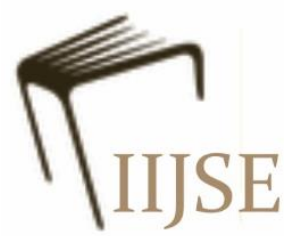

\title{
MENINGKATKAN PROFITABILITAS PERBANKAN SYARIAH MELALUI PEMBIAYAAN SEKTOR USAHA MIKRO, KECIL DAN MENENGAH
}

\author{
Purwanto ${ }^{1}$ \\ STAI Al-Husain, Magelang \\ purwanto@staia-sw.ac.id
}

\begin{abstract}
Abstrak
Kata kunci:

Pembiayaan,

UMKM,

Profitabilitas

Penyaluran pembiayaan pada sektor UMKM diharapkan bisa meningkatkan profitabilitas pada perbankan syariah, karena UMKM memiliki ketahanan terhadap kondisi perekonomian global, sehingga menyebabkan pembiayaan bermasalah relatif kecil. Pada akhirnya UMKM dapat meningkatkan priofitabilitas. Studi ini dilakukan pada perbankan syariah di Indonesia tahun 2016-2018. Data studi merupakan data sekunder yang bersumber dari OJK. Analisis data menggunakan analisis Structural Equation Modelling (SEM) dengan menggunakan Partial Least Square (PLS). Hasil pengujian menunjukkan bahwa tidak ada pengaruh yang signifikan antara pembiayaan dengan prinsip piutang terhadap tingkat profitabilitas bank syariah di Indonesia. Hasil penelitian lainnya adalah pembiayaan sektor UMKM memiliki pengaruh yang signifikan terhadap tingkat profitabilitas perbankan syariah di Indonesia pada tingkat signifikansi $90 \%$. Selanjutnya terdapat pengaruh tidak langsung antara penyaluran dengan prinsip piutang terhadap profitabilitas yaitu melalui sektor UMKM.
\end{abstract}

Abstract
Financing in the MSME sector is expected to increase profitability in
Islamic banking, because MSMEs have resilience to global economic
conditions, thus causing problematic financing to be relatively small. In the
end MSME can increase the priofitability of Islamic banking. This study
was conducted on Islamic banking in Indonesia in 2016-2018. Study data is
secondary data sourced from OJK. Data analysis using analysis of Structural
Equation Modeling (SEM) using Partial Least Square (PLS). The test results
show that there is no significant effect between financing and the principle
of receivables to the level of profitability of Islamic banks in Indonesia. The
results of other studies are that the financing of the MSME sector has a
significant influence on the profitability level of Islamic banking in
Indonesia at a 90\% significance level. Furthermore, there is an indirect
influence between financing and the principle of receivables to profitability,
namely through the MSME sector.

Keyword:

Financing,

Micro, Small \&

Medium

Enterprises

(MSME),

Profitability 


\section{A. Pendahuluan}

Usaha Menengah, Kecil dan Mikro (UMKM)

di Indonesia pada saat ini adalah tulang punggung dalam perekonomian Indonesia. Kondisi ini dapat dilihat dari besarnya kontribusi UMKM terhadap Produk Domestik Bruto (PDB) yang mencapai 60,34 persen dalam kurun waktu lima tahun terakhir. Selain itu menurut Gunartin, (2017) UMKM telah menyerap sebanyak 97,22 tenaga kerja. Dengan demikian UMKM telah berkontribusi besar terhadap penyerapan tenaga kerja dan juga perekonomian di Indonesia (Purwanto \& Majidun, 2018).

Besarnya kontribusi UMKM dalam perekonomian inilah UMKM menjadi pasar bagi lembaga keungan seperti perbankan syariah untuk menyalurkan pembiayaan. Penyaluran pembiayaan pada sektor UMKM lebih menguntungkan jika dibandingkan pada sektor lainnya. Sebagaimana Malik \& Suliswanto (2015) yang menyatakan bahwa UMKM memiliki kemampuan untuk bertahan dalam kondisi krisis, sehingga mampu menghindar dari keterpurukan akibat depresiasi rupiah yang menyebabkan peningkatan biaya produksi pada usaha yang banyak menggunakan input impor. Dengan keunikan dan kemampuan untuk bertahan dalam kondisi krisis inilah pembiayaan yang dilakukan oleh bank syariah pada sektor
UMKM lebih menguntungkan jika pada sektor usaha besar.

Dari uraian ini maka dapat dikatakan bahwa penyaluran pembiayaan pada sektor UMKM lebih berpotensi meningkatkan profitabilitas pada bank syariah. Profitabilitas pada bank syariah dapat diukur dengan Return on Asset (ROA). ROA menurut Afkar (2017) merupakan salah satu alat ukur untuk melihat kemampuan bank syariah dalam mengelola aset dalam usahanya mendapatkan laba. Profitabilitas juga dapat dilihat dari Net Operating Margin (NOM). NOM merupakan rasio yang digunakan untuk mengukur kemampuan bank syariah dalam mengelola aktiva produktifnya untuk menghasilkan laba. Semakin tinggi NOM maka semakin tinggi menunjukkan bahwa bank syariah dapat memaksimalkan aktiva produktifnya untuk menghasilkan laba (Tristiningtyas \& Mutaher, 2013).

Dengan demikian penyaluran pembiayaan pada sektor UMKM oleh perbankan syariah dapat meningkatkan profitabilitas bank syariah. Hasil penelitian yang dilakukan oleh Afkar (2017) membuktikan bahwa pembiayaan pada sektor UMKM memberikan dampak yang signifikan positif terhadap profitabilitas bank syariah. Demikian halnya penelitian yang dilakukan oleh Sahputra (2017) yang membuktikan bahwa pembiayaan 
oleh bank syariah pada sektor UMKM memiliki pengaruh yang signifikan terhadap perolehan laba. Namun hasil penelitian berbeda ditunjukkan oleh penelitian yang dilakukan oleh Mujaddid \& Sabila (2018) dimana hasil penelitiannya membuktikan bahwa pembiayaan pada sektor UMKM memiliki pengaruh yang negatif terhadap profitabilitas.

Selain melalui pembiayaan sektor UMKM, profitabilitas perbankan syariah juga dapat ditentukan oleh jenis penyaluran dana. Ada dua jenis penyaluran dana yang digunakan oleh bank syariah yaitu dengan prinsip bagi hasil dan dengan piutang. Penyaluran dengan prinsip bagi hasil biasanya menggunakan akad Musyarakah dan Mudharabah. Sementara penyaluran dana dengan prinsip piutang dapat menggunakan akad Murabahah, Qardh dan Istishna. Pada studi ini penyaluran pembiayaan lebih difokuskan pada penyaluran dana dengan prinsip piutang. Hal ini disebabkan porsi penyaluran dana dengan prinsip piutang lebih besar jika dibandingkan dengan prinsip pembiayaan bagi hasil.

Beberapa hasil penelitian yang dilakukan oleh Aqza \& Darwanto (2017) membuktikan bahwa pembiayan dengan prinsip piutang (Murabahah) memiliki pengaruh yang signifikan terhadap profitabilitas. Hasil serupa dengan penelitian yang dilakukan oleh
Sutrisno (2016), Almanaseer \& Alslehat (2016) dimana pembiayaan murabahah memiliki pengaruh positif terhadap profitabilitas yang diproksikan dengan ROA. Berbagai penelitian yang berkaitan dengan profitabilitas pada perbankan syariah sejauh ini masih menggunakan satu ukuran saja misalnya profitabilitas hanya menggunakan ROA, padahal profitabilitas juga dapat diukur dengan menggunakan NOM. Dengan demikian masih diperlukan penelitian yang menjadikan variabel profitabilitas sebagai variabel laten (tersembunyi), sehingga untuk mengukurnya dapat menggunakan variabel manifes (indikator). Untuk itu profitabilitas pada studi ini diukur dengan menggunakan dua indikator yaitu ROA dan NOM. Selain itu pada studi ini juga akan menjadikan variabel UMKM sebagai variabel intervening. Artinya penyaluran dana dalam bentuk piutang dapat meningkatkan profitabilitas jika disalurkan pada sektor UMKM. Dengan demikian penyaluran dalam bentuk piutang akan dapat meningkatkan profitabilitas jika penyaluran dana yang dilakukan oleh perbankan syariah diper-untukkan pada sektor UMKM.

\section{B. Metode Penelitian}

Jenis penelitian ini adalah penelitian kuantitatif dengan pendekatan kausalitas. Populasi dalam penelitian ini adalah laporan bulanan bank Umum Syariah dan Unit Usaha 
Syariah dalam kurun waktu Januari 2016 sampai dengan Oktober 2018. Dari jumlah populasi tersebut maka studi ini mengambil seluruhnya menjadi sampel penelitian, dengan demikian teknik penentuan sampel pada studi ini adalah teknik sampel jenuh.

Data yang digunakan dalam melakukan analisis adalah data sekunder. Data sekunder menurut Purwanto (2018) adalah data yang dikumpulkan tidak secara langsung oleh peneliti. Data sekunder tersebut diperoleh dari ojk.go.id. Data pembiayaan dengan prinsip piutang dalam studi ini ditentukan oleh tiga indikator yaitu piutang dengan akad Murabahah (Piu1), akad Qardh (Piu2) dan akad Istishna' (Piu3). Sementara itu untuk pembiayaan sektor Usaha Mikro, Kecil dan Menengah menggunakan dua indikator yaitu pembiayaan sektor Usaha Mikro, Kecil dan Menengah dalam bentuk Modal Kerja (Umkm1) dan dalam bentuk investasi (Umkm2). Sementara itu untuk profitabilitas diukur dengan dua Indikator yaitu ROA (Prof1) dan NOM (Prof2). Model penelitian dapat digambarkan sebagai berikut:

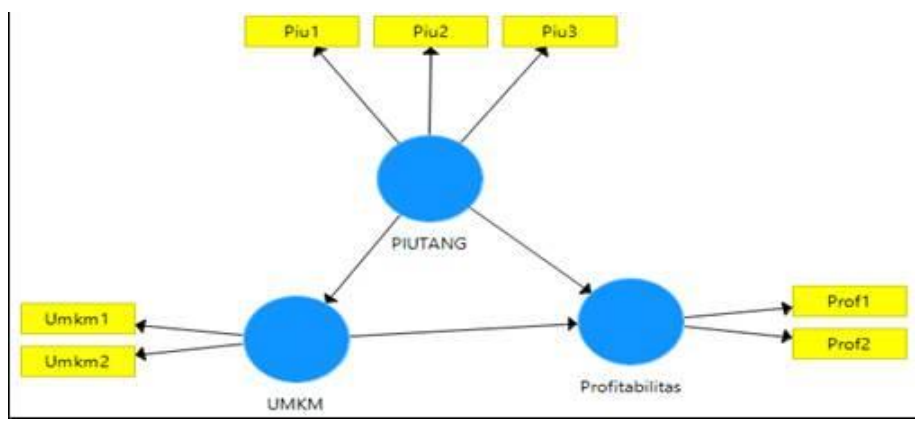

Gambar 1 Varibel dan Indikator
Guna menjawab permasalah yang maka studi ini menggunakan teknik analisis SEM dengan menggunakan PLS. PLS merupakan salah satu metode untuk melaksanakan model SEM. Alasan menggunakan PLS adalah PLS dapat digunakan pada saat dasar teori perancangan model lemah dan indikator pengukuran tidak memenuhi model pengukuran yang ideal selain itu PLS. Alasan lain menggunakan PLS adalah karena jumlah sampel yang sedikit dan juga dapat digunakan untuk semua jenis skala penelitian (Ghozali dan Latan, 2012).

Kriteria penilaian model PLS sebagaimana diajukan oleh Chin dalam Ghozali dan Latan (2012) adalah sebagaimana pada tabel berikut:

Tabel 1 Kriteria Penilaian PLS

\begin{tabular}{|c|c|c|}
\hline No & Kriteria & Penjelasan \\
\hline 1 & $\begin{array}{c}\text { Evaluasi } \\
\text { model } \\
\text { Pengukuran }\end{array}$ & $\begin{array}{l}\text { a. Nilai loading faktor diatas } \\
0,6 \\
\text { b. Setiap indikator memiliki } \\
\text { loading faktor lebih tinggi } \\
\text { terhadap konstruk nya } \\
\text { dibandingkan dengan } \\
\text { konstruk lainnya } \\
\text { c. Composite reliability } \\
\text { nilai harus }>0,60 . \\
\text { d. Averange Variance } \\
\text { Extracted }(A V E)>0.50 \\
\text { e. Cronbachs Alpha }>0.70\end{array}$ \\
\hline 2 & $\begin{array}{l}\text { Evaluasi } \\
\text { model } \\
\text { Struktural }\end{array}$ & $\begin{array}{l}\text { a. Dinyatakan berpengaruh } \\
\text { signifikan jika } \mathrm{P}_{\text {value }}< \\
0,05 . \\
\text { b. Nilai estimasi untuk } \\
\text { hubungan jalur dalam } \\
\text { model struktural harus } \\
\text { signifikan yang dapat } \\
\text { diperoleh dengan } \\
\text { prosedur bootstrapping. }\end{array}$ \\
\hline
\end{tabular}




\section{Hasil Penelitian}

Sebagaimana telah disebutkan sebelumnya, jika analisis dalam studi ini menggunakan analisis jalur atau SEM dengan menggunakan alat bantu Patial Least Square (PLS). Sebelum melakukan pengujian hipotesis maka terlebih dahulu harus dilakukan uji indikator.

\section{Uji Indikator}

Uji indikator atau disebut juga Outer model adalah menguji hubungan antara indikator terhadap variabel konstruknya. Dari uji indikator ini diperoleh output validitas dan realibilitas model yang diukur dengan kriteria: Convergent Validity, Discriminant Validity, dan Composite Reliability.

\section{a. Convergent Validity}

Convergent validity diukur dari korelasi antara skor indikator dengan konstruknya. Indikator individu dianggap valid jika memiliki nilai korelasi di atas 0,50 .

Tabel 2 Outer Loading (Convergen Validity)

\begin{tabular}{lcccc} 
& Piutang & Profit & UMKM & Ket \\
\hline Piu.1 & 0.954 & & & Valid \\
\hline Piu.2 & 0.855 & & & Valid \\
\hline Piu.3 & 0.971 & & & Valid \\
\hline Prof.1 & & 0.996 & & Valid \\
\hline Prof.2 & & 0.996 & & Valid \\
\hline UMKM.1 & & & 0.997 & Valid \\
\hline UMKM.2 & & & 0.979 & Valid \\
\hline
\end{tabular}

Sumber: Data primer diolah, 2019

Dari tabel di atas dapat diketahui bahwa terdapat nilai indikator yang memiliki nilai korelasi dibawah 0,50 . Hal ini menunjukkan bahwa semua indikator merupakan indikator yang baik, untuk mengukur variabel penelitian.

\section{b. Discriminant Validity}

Discriminant Validity diukur dari cross loading antara indikator dengan konstruknya. Indikator dinyatakan valid jika hubungan indikator dengan konstruknya lebih tinggi dibandingkan dengan hubungannya dengan konstruk yang lain. Hasil pengujian untuk discriminant validity tampak pada tabel berikut ini.

Tabel 3 Cross Loading (Discriminant

Validity)

\begin{tabular}{|c|c|c|c|c|}
\hline & & Profit & & \\
\hline 1 & & 656 & ו & \\
\hline & &, 324 & & \\
\hline & & 0,643 & & \\
\hline & & 0 & & \\
\hline & & 0.996 & & \\
\hline & & 0.601 & & \\
\hline & 0.944 & 0.679 & & \\
\hline \multicolumn{5}{|c|}{ Sumber: Data primer diolah, 2019} \\
\hline \multirow{2}{*}{\multicolumn{5}{|c|}{$\begin{array}{l}\text { Dari tabel di atas dapat diketahui bahwa } \\
\text { terdapat nilai loading factor untuk setiap } \\
\text { indikator pada variabel laten memiliki nilai } \\
\text { loading factor yang lebih besar dibanding nilai }\end{array}$}} \\
\hline & & & & \\
\hline \multicolumn{5}{|c|}{$\begin{array}{l}\text { loading factor jika dibandingkan dengan } \\
\text { variabel laten lainnya. Hal ini menunjukkan }\end{array}$} \\
\hline \multicolumn{5}{|c|}{ iabel la } \\
\hline
\end{tabular}




\section{c. Composite Reliability}

Konstruk dinyatakan reliabel apabila composite reliability memiliki nilai diatas 0,70. Reliability Blok Indicator yang mengukur suatu konstruk dapat dievaluasi dengan menggunakan output yang dihasilkan oleh PLS dari tabel composite reliability seperti pada tabel berikut ini.

Tabel 4 Nilai Composite Reliability

\begin{tabular}{lccc}
\hline Variabel & $\begin{array}{c}\text { Corbach's } \\
\text { Alpha }\end{array}$ & $\begin{array}{c}\text { Composite } \\
\text { Reliability }\end{array}$ & $\begin{array}{c}\text { Averange } \\
\text { Variance } \\
\text { Extracted }\end{array}$ \\
\hline Piutang & 0,919 & 0,954 & 0,861 \\
\hline Profitabilitas & 0,992 & 0,995 & 0,992 \\
\hline UMKM & 0,954 & 0,955 & 0,956 \\
\hline
\end{tabular}

Sumber: Data primer diolah, 2019

Tabel 4 diatas menunjukkan bahwa nilai Cronbachs Alpha > 0.70 nilai composite reliability berada $>0,70$ dan Averange Variance Extracted $(A V E)>0.50$. Dari hasil pengujian di atas maka dapat diambil kesimpulan bahwa semua variabel telah memiliki indikator yang memuaskan, yaitu nilai masing-masing variabel berada diatas nilai minimum. Berdasarkan nilai tersebut dapat dikatakan bahwa konsistensi dan stabilitas indikator yang digunakan sangat tinggi, oleh karena itu dapat disimpulkan bahwa semua variabel penelitian telah memiliki indikator yang reliabel.

Berdasarkan hasil uji terhadap indikator setiap variabel maka model yang digunakan pada penelitian ini sebagai berikut:

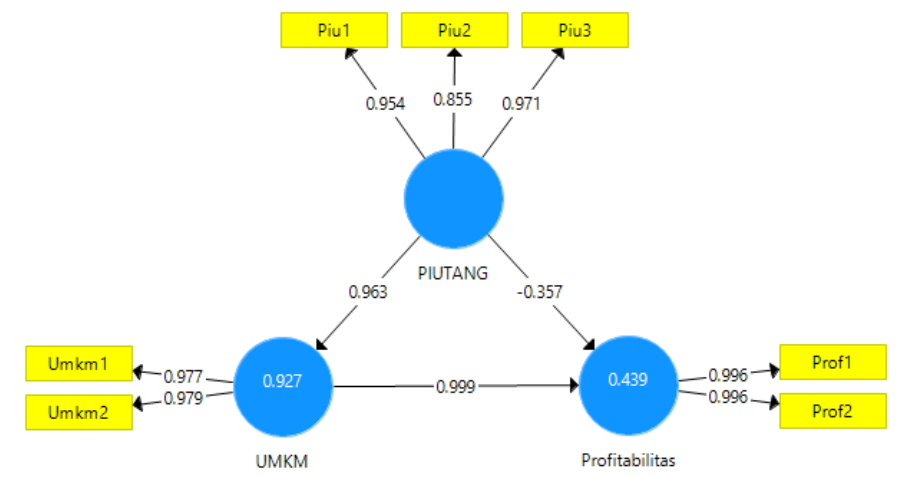

Gambar 2 Model Setelah Uji Indikator Uji Hipotesis Penelitian

Model Bootstraping setelah pengujian indikator dapat dilihat pada gambar berikut ini:

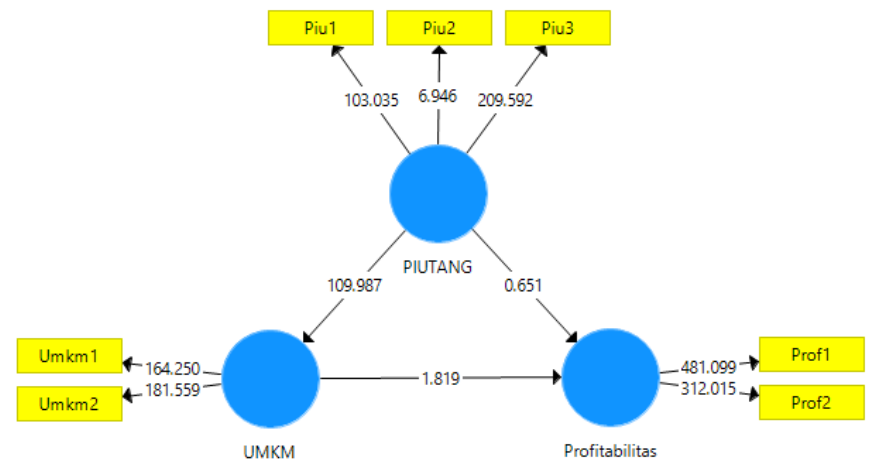

Gambar 3 Model Bootsraping

Adapun hasil dari pengujian hipotesis dapat dilihat pada tabel 5 berikut:

Tabel 5 Hasil Uji Hipotesis

\begin{tabular}{|c|c|c|c|c|}
\hline Pengaruh & $\begin{array}{c}\mathbf{R} \\
\text { Square }\end{array}$ & $\begin{array}{c}\text { T } \\
\text { Statistic }\end{array}$ & $\begin{array}{c}\mathbf{P} \\
\text { Value }\end{array}$ & $\begin{array}{c}\text { Kesimp } \\
\text { ulan }\end{array}$ \\
\hline $\begin{array}{l}\text { Piutang } \rightarrow \\
\text { Profitabilitas }\end{array}$ & \multirow{2}{*}{0.439} & 0,653 & 0.515 & Ditolak \\
\hline $\begin{array}{l}\text { UMKM } \rightarrow \\
\text { Profitabilitas }\end{array}$ & & 1,819 & 0,069 & $\begin{array}{c}\text { Diterim } \\
\mathrm{a}^{* * *}\end{array}$ \\
\hline $\begin{array}{l}\text { Piutang } \rightarrow \mathrm{U} \\
\mathrm{MKM} \rightarrow \\
\text { Profitabilitas }\end{array}$ & & 1,805 & 0,071 & $\begin{array}{l}\text { Diterim } \\
\text { a*** }\end{array}$ \\
\hline $\begin{array}{l}\text { Sumber: Data } \\
* \text { Sig Level } \\
\text { **Sig Leve } \\
* * * \text { Sig Lev }\end{array}$ & $\begin{array}{l}\text { imer diol } \\
5 \% \\
90 \%\end{array}$ & 019 & & \\
\hline
\end{tabular}


Dari hasil pengujian di atas dapat diambil kesimpulan bahwa tidak ada pengaruh yang signifikan antara pembiayaan dengan prinsip piutang terhadap tingkat keuntungan atau profitabilitas bank syariah di Indonesia tahun 2016-2018. Hasil studi lainnya adalah pembiayan sektor UMKM memiliki pengaruh yang signifikan terhadao tingkat profitabilitas perbankan syariah di Indonesia tahun 20162018 pada tingkat signifikansi 90\%. Hasil hipotesis yang ke tiga adalah pembiayaan dengan akad piutang memiliki pengaruh yang signifikan terhadap profitabilitas perbankan syariah di Indonesia tahun 2016-2018 melalui pembiayaan UMKM.

\section{Pembahasan}

Dari hasil pengujian ditemukan bahwa bahwa tidak ada pengaruh yang signifikan antara penyaluran dana dalam bentuk piutang terhadap tingkat profitabilitas bank syariah di Indonesia tahun 2016-2018. Hasil penelitian ini tentunya bertolak belakang dengan hasilhasil penelitian yang telah dilakukan oleh Aqza \& Darwanto (2017) yang membuktikan bahwa pembiayan dengan prinsip piutang (Murabahah) memiliki pengaruh yang signifikan terhadap profitabilitas. Demikian halnya dengan penelitian yang dilakukan oleh Sutrisno (2016), Almanaseer \& Alslehat (2016) dimana pembiayaan murabahah memiliki pengaruh positif terhadap profitabilitas yang diproksikan dengan ROA. Berbedanya hasil penelitian ini dengan penelitian sebelumnya menunjukkan bahwa penyaluran dana dalam bentuk piutang tidak mampu meningkatkan profitabilitas perbankan syariah. Ketidakmampuan penyaluran dana dalam meningkatkan profitabilitas perbankan syariah disebabkan oleh tingginya pembiayaan bermasalah atau Non-Performing Financing (NPF). NPF merupakan perbandingan antara pembiayaan non lancar terhadap jumlah seluruh pembiayaan yang disalurkan. Semakin tinggi NPF ini maka tingkat profitabilitas perbankan syariah akan mengalami penurutan (Tristiningtyas \& Mutaher, 2013).

Hasil penelitian selanjutnya adalah ada pengaruh yang signifikan antara penyaluran dana pada sektor UMKM terhadap tingkat profitabilitas bank syariah di Indonesia tahun 2016-2018. Hasil penelitian ini mendukung hasil penelitian yang dilakukan oleh Afkar (2017) dan Sahputra (2017) yang membuktikan bahwa pembiayaan pada sektor UMKM memberikan dampak yang signifikan positif terhadap profitabilitas bank syariah. Dengan demikian hasil penelitian ini bertentangan dengan hasil penelitian yang dilakukan oleh Mujaddid \& Sabila (2018) dimana hasil penelitiannya membuktikan bahwa pembiayaan pada sektor UMKM 
memiliki pengaruh yang negatif terhadap profitabilitas.

Hasil penelitian ini menunjukkan bahwa penyaluran dana pada sektor UMKM dapat meningkatkan pendapatan perbankan syariah. Hasil ini menunjukkan bahwa penyaluran dana pada sektor UMKM merupakan pasar yang tepat bagi perbankan syariah. Sektor UMKM pada umumnya adalah sektor riil, sehingga pada kondisi fluktuasi perekonomian dunia saat ini pembiayaan pada sektor riil tidak terkait secara langsung. Dengan demikian penyaluran dana pada sektor UMKM tidak mengalami pembiyaan bermasalah yang tinggi, sehingga bank syariah tidak harus melakukan penghapusan kredit dengan modal yang dimiliki.

Hasil penelitian selanjutnya adalah terdapat pengaruh yang signifikan antara penyaluran dana dalam bentuk piutang terhadap tingkat profitabilitas bank syariah di Indonesia tahun 2016-2018 melalui pembiayaan pada sektor UMKM. Penyaluran dana oleh bank syariah dengan prinsip piutang tidak mampu meningkatkan profitabilitas perbankan syariah, namun ketika penyaluran dana yang menggunakan piutang dilakukan pada sektor UMKM maka profitabilitas perbankan syariah akan mengalami peningkatan. Dengan demikian ada pengaruh tidak langsung antara penyaluran dengan prinsip piutang terhadap profitabilitas yaitu melalui sektor UMKM.

\section{E. Penutup}

Dari hasil pengujian dapat diambil kesimpulan bahwa tidak ada pengaruh yang signifikan antara pembiayaan dengan prinsip piutang terhadap tingkat keuntungan atau profitabilitas bank syariah di Indonesia tahun 2016-2018. Hasil penelitian lainnya adalah pembiayan sektor UMKM memiliki pengaruh yang signifikan terhadap tingkat profitabilitas perbankan syariah di Indonesia tahun 20162018 pada tingkat signifikansi 90\%. Hasil studi selanjutnya yaitu ada pengaruh tidak langsung antara penyaluran dengan prinsip piutang terhadap profitabilitas yaitu melalui sektor UMKM.

\section{F. Daftar Pustaka}

Afkar, T. (2017). Pengaruh Pembiayaan Usaha Mikro, Kecil, Menengah Mendapatkan Laba Dari Aset Perbankan Syariah Di Indonesia. Al-Uqud: Journal of Islamic Economics, 1(2), 183-201.

Almanaseer, S. R., \& Alslehat, Z. A. (2016). The Impact of Financing Revenues of the Banks on their Profitability: An Empirical Study on Local Jordanian Islamic banks. European Journal of Business and Management, 8(12), 195-202.

Aqza, Y., \& Darwanto. (2017). Pengaruh pembiayaan murabahah, musyarakah, dan biaya transaksi terhadap profitabilitas bank pembiayaan rakyat syariah. Iqtishadia, 10(1), 225-245. 
Ghozali, I., \& Latan, H. (2012). Partial Least Square, Konsep Teknik, dan Aplikasi menggunakan program SmartPLS 3.0 untuk Penelitian Empiris. Semarang: Badan Penerbit Universitas Diponegoro.

Gunartin. (2017). Penguatan UMKM Sebagai Pilar Membangun Ekonomi Bangsa. Eduka: Jurnal Pendidikan Hukum Dan Bisnis, 5(1), 59-74.

Malik, N., \& Suliswanto, M. S. W. (2015). Peran Pembiayaan Perbankan Syariah Terhadap Peningkatan Keunggulan Kompetitif Sektor UMKM. Malang: FEB Universitas Muhammadiyah Malang.

Mujaddid, F., \& Sabila, G. F. (2018). Pengaruh pembiayaan umkm dan rasio keuangan terhadap pertumbuhan laba bank umum syariah di indonesia. Jurnal Ekonomi Islam, 9(2), 119-136.

Purwanto. (2018). Teknik Penyusunan Instrumen Uji Validitas dan Reliabilitas Penelitian Ekonomi Syariah. Magelang: StaiaPress.

Purwanto, \& Majidun, A. (2018). Mengembangkan Budaya Kewirausahaan untuk Mahasiwa Program Studi Ekonomi Syariah. In PROSEDING Seminar Nasional Pendidikan Ekonomi dan Call for Paper Tema. Surakarta: Program Magister Pendidikan Ekonomi Universitas Sebelas Maret.

Sahputra, N. (2017). Pengaruh pembiayaan usaha mikro kecil menengah (umkm) terhadap laba operasional pada pt. Bri syariah cabang medan. Al-Hadi, 2(2), 467-476.

Sutrisno. (2016). The effects of financing and risks on the performance of Islamic Bank: Empirical evidence from Indonesian
Islamic Bank. Business and Management Research, 6(3), 29-36.

Tristiningtyas, V., \& Mutaher, O. (2013). Analisis Faktor-Faktor yang Mempengaruhi Kinerja Keuangan Pada Bank Umum Syariah di Indonesia. Jurnal Akuntansi Indonesia, 3(2), 131-145. 